\title{
The Third Wave of the COVID-19 Arrived in Afghanistan: A Severe Case with Skin Manifestation
}

\author{
Abdul Wahed Sediqi ${ }^{1,2}$ \\ Arash Nemat $\left.{ }^{3}\right)^{3}$ \\ Nahid Raufi ${ }^{4}$ \\ Abdullah Asady $\mathbb{D}^{3}$ \\ 'Department of Cardiology, Ariana \\ Medical Complex, Kabul, Afghanistan; \\ ${ }^{2}$ Department of Cardiology, Ali Abad \\ Teaching Hospital, Kabul University of \\ Medical Sciences, Kabul, Afghanistan; \\ ${ }^{3}$ Department of Microbiology, Kabul \\ University of Medical Sciences, Kabul, \\ Afghanistan; ${ }^{4}$ Department of \\ Dermatology, Maiwand Teaching \\ Hospital, Kabul University of Medical \\ Sciences, Kabul, Afghanistan
}

\begin{abstract}
The COVID-19 is an ongoing global pandemic that has put the world in a devastating situation. The virus is able to attack multiple body systems and cause a variety of clinical problems ranging from asymptomatic to critical cases. Although young individuals are more likely to suffer milder forms of the disease, critical cases also might happen. Recent literature has revealed that, along with other clinical symptoms, skin manifestations have also progressively grown. In Afghanistan where COVID-19 has entered into a third wave, many people do not take the initial mild symptoms seriously to prevent further spreading in the community. We report symptoms of skin rash, fatigue, muscle pain, dry cough and fever at the onset of the disease, followed by rapid lung damage in a 23-yearold young adult, who did not have any preexisting risk factors. This case highlights the importance of urgent skin assessment of the COVID-19 patient complaining of any skin symptoms.
\end{abstract}

Keywords: COVID-19, skin rash, SARS-CoV-2, Kabul, case report

\section{Introduction}

Coronavirus disease-2019 (COVID-19) is an infectious disease caused by a recently discovered type of coronaviruses. ${ }^{1}$ Globally, as of 23 July 2021, there have been 192,284,207 confirmed cases of COVID-19, including 4,136,518 deaths, reported by World Health Organization (WHO). ${ }^{2}$ In Afghanistan, as of late July 2021, the number of confirmed cases reached to 143,439 including 6357 deaths. $^{3}$ It can be assumed that the actual figures of infected people and deaths might be higher than reported as many parts of the country are not accessible to statistical counts and measurements. 4

People aged 60 years and above are at higher risk of getting serious forms of the disease. ${ }^{5}$ Young individuals are more likely to get milder forms of the infection. ${ }^{6}$ WHO reported that, among those who develop symptoms, only $15 \%$ become seriously ill and require oxygen and only 5\% of them would become critically ill and require intensive care services. ${ }^{7}$

Although COVID-19 is commonly reported to cause respiratory symptoms, other manifestations have also been reported, including skin lesions. ${ }^{8}$ Studies also highlight the differences in the time of symptoms onset and their polymorphic nature. ${ }^{9}$ Among COVID-19 patients with skin lesions, the majority of them experience the symptoms shortly after or concurrently with the onset of systemic symptoms. Only in $7 \%$ of
Correspondence: Arash Nemat Department of Microbiology, Kabul University of Medical Sciences, 3rd

District, Kabul, I00I, Afghanistan

Tel +93706717987

Email dr.arashnemat@yahoo.com 
them, topical skin rashes appear before systemic symptoms. ${ }^{10}$ Long-term mandatory use of face masks has also been reported to cause skin problems. ${ }^{11}$

In this report, we present the critical case of a young male infected with COVID-19 who suffered from fever, muscle pain, dry cough and skin rashes as presenting symptoms followed by rapid lung damage.

\section{Case Presentation}

A 23-year-old male patient came to the Emergency Department of Ariana Medical Complex, a private hospital in Kabul, Afghanistan, with dry cough, fever, muscle pain and diffuse palpable purpura on the skin of his left leg and lower part of abdomen (Figure 1).

The patient had started feeling unwell 15 days before, followed by fatigue, muscle pain, mild fever, dry cough and skin rash over the last five days. On the last day, the symptoms were accompanied by dry cough and difficulty breathing, which caused him to be referred to the hospital. On physical examination, the patient had high fever $\left(38.4^{\circ} \mathrm{C}\right)$, low oxygen saturation $(\mathrm{SpO} 2=77 \%)$, and dyspnea with wet rales in both lungs. Other systems were normal. He had no history of medication and underlying comorbidities. He did not have alcohol consumption and cigarette smoking habits, which are the known risk factors for developing severe COVID-19 illness. $^{12}$

Warm O2-therapy started immediately in the emergency ward. Real-Time Reverse Transcriptase Polymerase Chain Reaction (RT-PCR) advised to confirm the initial diagnosis. After 24 hours, the PCR confirmed

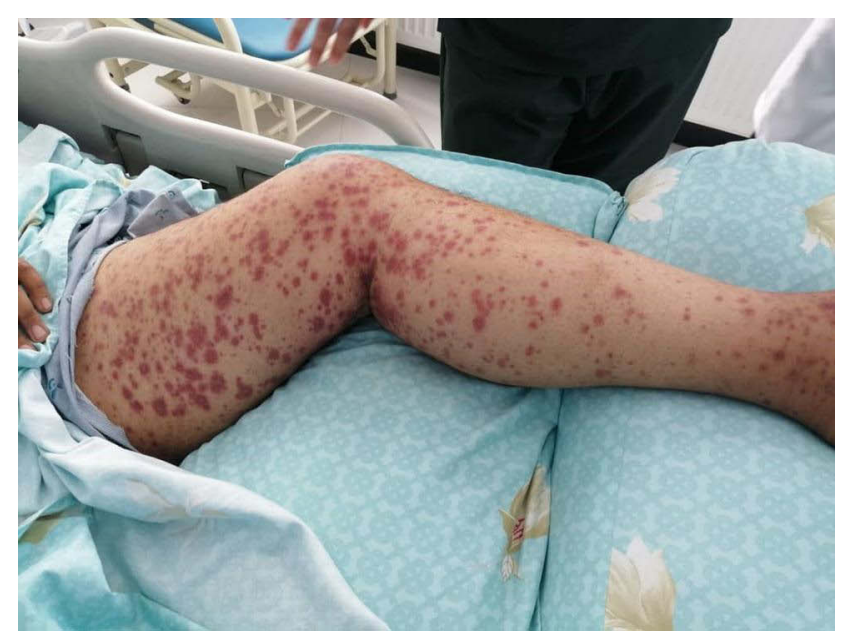

Figure I Clinical image of diffuse palpable purpura on the left leg in a COVID-19 confirmed case. The 23 years old male patient had confirmed COVID-19 infection. Erythema with dry cough were the initial symptoms which quickly followed by fever and shortness of breath. that the patient had been infected with COVID-19. Bilateral ground glass opacities were noted on Chest Computed Tomography (CT) (Figure 2). The patient was admitted to the isolation ward.

Dexamethasone 6 Milli grams (mg) once daily for 10 days with invasive mechanical ventilation was considered standard general management. Prophylactic anticoagulation was implemented to maintain the prothrombotic state and prevent cloth formation. Infusion of Paracetamol 1.5 grams daily used to control fever and empirical usage of antibiotics, ie $625 \mathrm{mg}$ Co-Amoxiclav and Clavulanate twice a day for 10 days, was advised to prevent secondary bacterial infection. Meanwhile, chest physiotherapy and nutritional support were also considered to accelerate the course of improvement.

During the treatment, the patient's symptoms, including skin rash and lung problems, were improved, and he was discharged on day 19th of admission. Five days later, the patient was re-examined for follow-up investigation. Chest CT scan showed improvement of the lung lesions (Figure 3).

\section{Discussion}

Different percentages of COVID-19 cases in different age groups do not reflect that the virus merely infects older people. Also, hospitalizations and deaths are distributed along these age-lines. ${ }^{12}$ Therefore, it is essential for all age groups to equally follow hygiene practice and social distance, and to avoid careless behaviors. ${ }^{13}$

In this report, we describe the case of a young patient who was in perfect health before the onset of COVID-19 symptoms. His complaints included fatigue, muscle pain, mild fever, dry cough and redness of his left leg, followed by respiratory distress. The case suggests that serious cases of COVID-19 may develop in young adults who do not have any history of underlying diseases.

Skin lesion was an uncommon symptom of the case. The first scientific report about skin involvement in COVID-19 patients was reported in China. ${ }^{14}$ Since then, various publications reported cutaneous manifestations associated with COVID-19. The most common cutaneous manifestations reported are vesicular eruptions, petechial/ purpuric rashes, acral lesions, livedoid lesions, urticarial rash, and maculopapular-erythematous rash. ${ }^{15}$ These manifestations may be presented as the first symptoms or may be associated with severity of SARS-CoV-2 infection. ${ }^{16}$ Vasculopathy-related skin manifestations have been reported in severe COVID-19 patients, and they correlate 


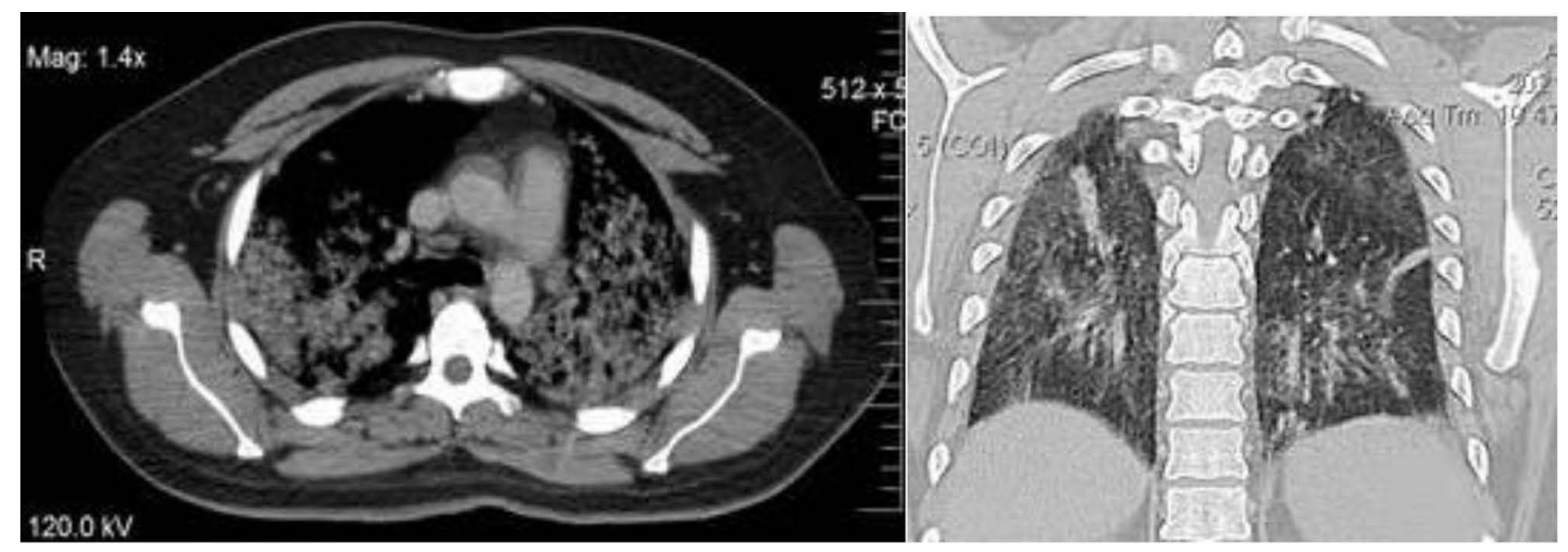

Figure 2 Coronal and axial images demonstrate opacities in both lungs.

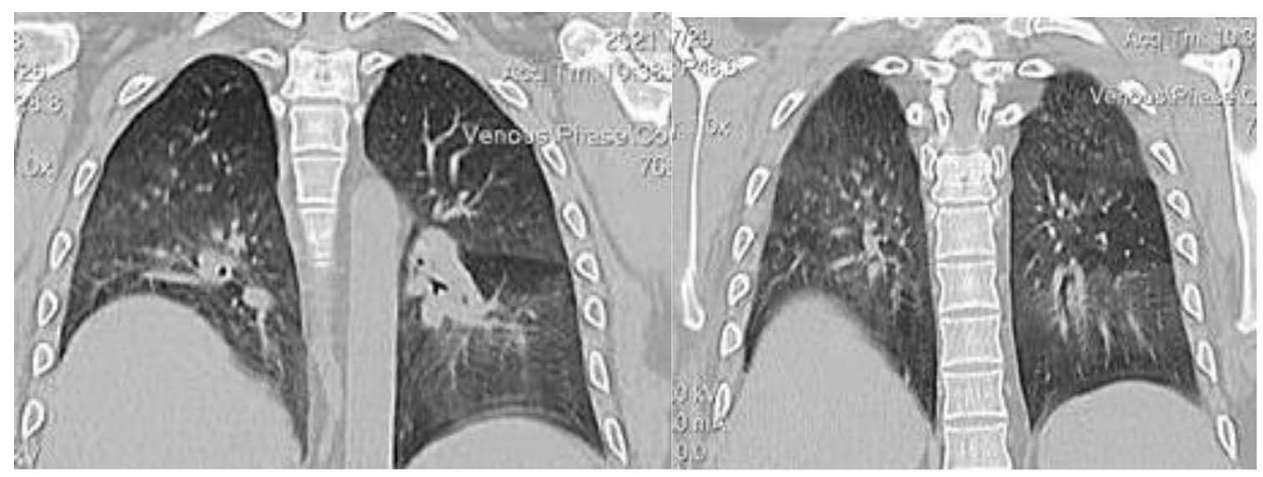

Figure 3 Selected chest CT images show interval resolution of bilateral consolidation.

with poor prognosis of the disease. Therefore, early detection of dermatologic signs may provide prognostic values by indicating serious complications due to COVID-19 and by monitoring disease severity. ${ }^{17}$

In light of the rareness of the original reports from Middle-Eastern countries and the global racial disparities in infection and mortality rate, the scientists should be encouraged to report whatever possible cases of skin manifestations in confirmed COVID-19 patients to help create a registry related to their ethnic population. These papers could assist in early diagnosis and potentially better health outcomes. While awaiting these data, it is crucial for all health professionals to be knowledgeable of the wide varieties of dermatological manifestations in patients with COVID-19. ${ }^{18}$

In a country like Afghanistan, where people ignore or cannot afford to pay for preventive measures and have little knowledge about the third wave of this highly contagious infection, this report is important from a public health point of view. ${ }^{19}$ The infection among young adults may contribute to community transmission of the disease, including to persons at higher risk of getting severe illness.

The Ministry of Public Health Afghanistan and other responsible organizations and the people at large should emphasize targeted mitigation strategies to reduce initial infections and transmission among young adults, including prohibition of community gatherings during this tough time. All persons, including young adults, should take extra precautions to avoid transmission to family and community members, particularly to the elder people and those who have underlying medical conditions. In addition, the emergency departments have to update their screening and triage procedures to timely identify suspected cases and isolate them for further evaluations.

\section{Conclusion}

Although severe cases of the COVID-19 are more common in elder people particularly with underlying comorbidities, adults may also experience such forms. Skin lesions have also been found to be associated with 
COVID-19. This case highlights the importance of urgent skin assessment of the COVID-19 patient complaining of any skin symptoms.

\section{Ethical Approval and Consent for Publication}

The study was approved by the Kabul University of Medical Sciences Ethical Committee (KUMS-EC-1104-21). Written informed consent was obtained from the patient for publication of this case report and accompanying images.

\section{Disclosure}

The authors report no conflicts of interest in this work.

\section{References}

1. Nemat A, Raufi N, Sediqi MF, Rasib AR, Asady A. Knowledge, attitudes, and practices of medical students regarding COVID-19 in Afghanistan: a Cross-Sectional Study. Risk Manag Healthc Policy. 2021;14:1491-1497. doi:10.2147/rmhp.s308039

2. World Health Organization. WHO Coronavirus (COVID-19) dashboard; July 23, 2021. Available from: https://covid19. who.int/?gclid= CjwKCAjwuvmHBhAxEiwAWAYj-I0aPqURCIK28bbV6aDzZly3pu 34_U1LJA8gqJgAEckAEyLIXwKxhoCtZ4QAvD_BwE. Accessed November 6, 2021.

3. World Health Organization. Afghanistan; 2021. Available from: https://covid19.who.int/region/emro/country/af. Accessed November 6, 2021.

4. Nemat A, Asady A, Raufi N, et al. A survey of the healthcare workers in Afghanistan during the COVID-19 pandemic. Am J Trop Med Hyg. 2021;104(2):537.

5. World Health Organization. Coronavirus disease (COVID-19). Available from: https://www.who.int/emergencies/diseases/novelcoronavirus-2019/question-and-answers-hub/q-a-detail/coronavirusdisease-covid-19. Accessed November 6, 2021.

6. Centers for Disease Control and Prevention (CDC). Changing age distribution of the COVID-19 pandemic. Available from: https:// www.cdc.gov/mmwr/volumes/69/wr/mm6939e1.htm\#suggestedcita tion. Accessed November 6, 2021.
7. World Health Organization. Coronavirus disease (COVID-19)/ Coronavirus disease - answers. Available from: https://www.who.int/emer gencies/diseases/novel-coronavirus-2019. Accessed November 6, 2021.

8. Marzano AV, Cassano N, Genovese G, Moltrasio C, Vena G. Cutaneous manifestations in patients with COVID-19: a preliminary review of an emerging issue. Br J Dermatol. 2020;183(3):431-442. doi:10.1111/bjd.19264

9. Gisondi P, Di Leo S, Bellinato F, Cazzaniga S, Piaserico S, Naldi L. Time of onset of selected skin lesions associated with COVID-19: a systematic review. Dermatol Ther. 2021;11(3):695-705.

10. Jamshidi P, Hajikhani B, Mirsaeidi M, et al. Skin manifestations in COVID-19 patients: are they indicators for disease severity? A systematic review. Front Med. 2021;8. doi:10.3389/fmed.20 21.634208

11. Damiani G, Gironi LC, Pacifico A, et al. Masks use and facial dermatitis during COVID-19 outbreak: is there a difference between $\mathrm{CE}$ and non-CE approved masks? Multi-center, real-life data from a large Italian cohort. Ital J Dermatol Venereol. 2021;156(2):2 20-225. doi:10.23736/S2784-8671.21.06895-4

12. Leong R, Lee T-SJ, Chen Z, Zhang C, Xu J. Global temporal patterns of age group and sex distributions of COVID-19. Infect Dis Rep. 2021;13:582-596. doi:10.3390/idr13020054

13. Kaur H, Kaur S, Pareek S. Awareness assessment regarding COVID-19 among population-a Cross-Sectional Online Study. Int J Nurs Midwifery Res. 2020;7:16-20. doi:10.24321/2455.9318.202013

14. Guan W-J, Ni Z-Y, Hu Y, et al. Clinical characteristics of coronavirus disease 2019 in China. $N$ Engl J Med. 2020;382(18):1708-1720. doi:10.1056/NEJMoa2002032

15. Fernández-Lázaro D, Garrosa M. Identification, mechanism, and treatment of skin lesions in COVID-19: a review. Viruses. 2021;13 (10):1916. doi:10.3390/v13101916

16. Mawhirt SL, Frankel D, Diaz AM. Cutaneous manifestations in adult patients with COVID-19 and dermatologic conditions related to the COVID-19 pandemic in health care workers. Curr Allergy Asthma Rep. 2020;20(12):75. doi:10.1007/s11882-020-00974-w

17. Suchonwanit P, Leerunyakul K, Kositkuljorn C. Diagnostic and prognostic values of cutaneous manifestations in COVID-19. Dermatol Ther. 2020;33:e13650-e13650. doi:10.1111/dth.13650

18. Abdelmaksoud A, Shakshouk H, Goldust M, et al. Cutaneous manifestation of COVID-19 reporting from Middle-Eastern countries: a point of view! Int J Dermatol. 2020;59(12):1547-1548. doi:10. 1111/ijd.15258

19. TOLONEWS. 1647 new cases of COVID-19, 78 deaths reported in Afghanistan. Available from: tolonews.com/health-172859. Accessed November 6, 2021.
International Medical Case Reports Journal

\section{Publish your work in this journal}

The International Medical Case Reports Journal is an international, peer-reviewed open-access journal publishing original case reports from all medical specialties. Previously unpublished medical posters are also accepted relating to any area of clinical or preclinical science. Submissions should not normally exceed 2,000 words or 4

\section{Dovepress}

published pages including figures, diagrams and references. The manuscript management system is completely online and includes a very quick and fair peer-review system, which is all easy to use. Visit http://www.dovepress.com/testimonials.php to read real quotes from published authors. 